\title{
ADSORÇÃO DE AMINOÁCIDOS SOBRE MINERAIS E A ORIGEM DA VIDA
}

\author{
Dimas A. M. Zaia* \\ Departamento de Química, Centro de Ciências Exatas, Universidade Estadual de Londrina, CP 6001, \\ 86051-990 Londrina - PR, Brasil \\ Cássia Thaïs B. V. Zaia \\ Departamento de Ciências Biológicas, Centro de Ciências Fisiológicas, Universidade Estadual de Londrina, \\ 86051-990 Londrina - PR, Brasil
}

Recebido em 30/3/05; aceito em 15/7/05; publicado na web em 6/3/06

\begin{abstract}
ADSORPTION OF AMINO ACIDS ON MINERALS AND THE ORIGIN OF LIFE. Minerals adsorb more readily amino acids with charged $\mathrm{R}$ groups than those with uncharged $\mathrm{R}$ groups, so that the incorporation of amino acids with charged $\mathrm{R}$ groups into peptides would be more frequent than that of amino acids with uncharged $\mathrm{R}$ groups. However, $74 \%$ of the amino acids in the proteins of modern organisms contain uncharged $\mathrm{R}$ groups. Thus, what could have been the mechanism that produced peptides/ proteins with more amino acids with uncharged $\mathrm{R}$ groups than precursors with charged $\mathrm{R}$ groups? The lipid world offers an alternative view of the origin of life. In the present paper, several other mechanisms are also discussed.
\end{abstract}

Keywords: adsorption; minerals; amino acids.

\section{INTRODUÇÃOO}

Podemos dizer que a grande maioria das reações químicas, que ocorrem em todos os seres vivos do nosso planeta, de alguma forma envolve proteínas e peptídeos e, em alguns casos, aminoácidos ${ }^{1}$. Por este motivo, a questão da formação de aminoácidos na Terra primitiva e sua condensação para peptídeos é um assunto extremamente importante para a química prebiótica. Neste artigo vamos partir do pressuposto que aminoácidos existiam em uma quantidade razoável na Terra primitiva. Podemos considerar, com uma boa margem de segurança, que esta suposição esteja correta visto que aminoácidos são facilmente sintetizados em diversos ambientes da química prebiótica, tais como mistura gasosas tanto de atmosferas redutoras como oxidantes ${ }^{2-5}$; reações em estado sólido ${ }^{6}$; reações simulando fontes hidrotermais ou em meio aquoso ${ }^{7-11}$. Também devemos lembrar que cometas e meteoros podem ter contribuído com uma parcela dos aminoácidos existentes na Terra primitiva ${ }^{12,13}$. Logo após o celebre experimento de Miller $^{2}$, diversos pesquisadores colocaram a seguinte questão: os aminoácidos formados na atmosfera, que não fossem destruídos pela forte radiação ultravioleta do nosso jovem Sol, cairiam no mar da Terra primitiva e sendo este mar muito grande (como é nos dias de hoje) os aminoácidos seriam muito diluídos impossibilitando a formação de peptídeos ou proteínas e, desta forma, impedindo a evolução molecular. O mesmo problema ocorreria para o caso dos aminoácidos produzidos em fontes hidrotermais ou no mar ou trazidos por cometas ou meteoros que caíssem no mar. Para resolver o problema da grande diluição dos aminoácidos, Bernal ${ }^{14}$ sugeriu que os minerais tivessem um papel importante na pré-concentração dos aminoácidos, devido a suas propriedades de bons adsorventes, e agissem também como catalisadores na formação dos peptídeos e proteínas. Portanto, os minerais poderiam ter selecionado os aminoácidos e catalisado sua reação para formação de peptídeos e proteínas. Neste artigo vamos tratar da questão da participação dos minerais na pré-concentração dos aminoácidos.

*e-mail: damzaia@uel.br

\section{ADSORÇÃO DE BIOMOLÉCULAS SOBRE MINERAIS}

Devemos salientar que os minerais obviamente tiveram provavelmente também uma participação importante na adsorção de outras biomoléculas diferentes dos aminoácidos. Na literatura está descrita a adsorção sobre minerais de adenosina mono ou di ou tri fosfato (AMP, ADP, ATP, respectivamente), bases de ácidos nucléicos, cianeto, etc ${ }^{15-21}$. A formação de biopolímeros também está descrita, sendo que peptídeos e polinucleotídeos são os mais comumente estudados $22-25$.

\section{ADSORÇÃO DE AMINOÁCIDOS SOBRE MINERAIS}

O principal objetivo deste trabalho é discutir as implicações da adsorção de aminoácidos sobre minerais em relação à origem dos peptídeos e proteínas, assim como a origem da vida.

$\mathrm{O}$ artigo de revisão publicado por Lahav e Chang ${ }^{26}$ mostra os resultados dos coeficientes de adsorção para vários aminoácidos adsorvidos sobre diversos minerais e é um excelente ponto de partida para o problema que vamos discutir. Os coeficientes de adsorção para os ácidos glutâmico e aspártico (ambos com grupos R carregados negativamente) sobre a apatita são duas vezes maiores que para a glicina (grupo R não polar alifático) e estes coeficientes podem ser até três vezes maiores, dependendo do método de medi$\mathrm{da}^{26}$. Nesta mesma revisão estão descritos os coeficientes de adsorção de diversos aminoácidos para a ilita. Novamente observamos uma grande diferença entre os coeficientes de adsorção de glicina/alanina (grupo R não polar alifático) e de histidina (grupo $\mathrm{R}$ positivamente carregado), assim como para os coeficientes de adsorção sobre a montmorilonita dos aminoácidos alanina/leucina/ glicina (grupo R não polar alifático) e a arginina/histidina/lisina (grupo R positivamente carregado) ${ }^{26}$. Portanto, podemos concluir pelos dados apresentados nessa revisão que aminoácidos carregados positiva ou negativamente são adsorvidos sobre minerais em uma quantidade muito maior que os aminoácidos que não possuem o grupo R carregado. Paecht-Horowitz ${ }^{27}$ observou que a histidina (grupo $\mathrm{R}$ carregado positivamente) foi adsorvida em uma quanti- 
dade quatro vezes maior que a alanina-adenilato sobre a montmorilonita. Tanaka et ll. $^{28}$ observaram que a hidroxiapatita tem uma grande afinidade por ácido aspártico (grupo $\mathrm{R}$ negativamente carregado) e lisina (grupo $\mathrm{R}$ positivamente carregado), porém tem uma pequena afinidade para alanina (grupo $\mathrm{R}$ não polar alifático). Henrichs e Sugai ${ }^{29}$ mostraram que a adsorção da lisina (grupo R positivamente carregado) era muito maior que a da alanina e leucina (grupo R não polar alifático) em sedimentos provenientes da baia de Resurrection, Alaska. Bentaleb et al. ${ }^{30}$ estudaram a adsorção dos aminoácidos glicina, lisina e ácido glutâmico sobre hematita $\left(\alpha-\mathrm{Fe}_{2} \mathrm{O}_{3}\right)$ e observaram que a lisina (grupo $\mathrm{R}$ positivamente carregado) e o ácido glutâmico (grupo $\mathrm{R}$ negativamente carregado) foram muito mais adsorvidos que a glicina (grupo $\mathrm{R}$ não polar alifático). Mellersh e Wilkinson ${ }^{31}$ verificaram que o ácido poliadenílico liga-se à sílica gel e que, de um pool de 18 aminoácidos, somente L-lisina e L-arginina (ambos com grupos $\mathrm{R}$ positivamente carregados) ligaram-se no sistema constituído por sílica/ácido poliadenílico. Zaia et al. ${ }^{32}$ realizaram um estudo da adsorção da alanina (grupo $\mathrm{R}$ não polar alifático), tirosina (grupo $\mathrm{R}$ aromático polar em $\mathrm{pH}$ alto), ácido glutâmico (grupo $\mathrm{R}$ negativamente carregado) e lisina (grupo $\mathrm{R}$ positivamente carregado) sobre areia do mar, observando que somente a lisina adsorveu em uma quantidade apreciável sobre esta areia. Churchill et al. ${ }^{33}$ utilizaram a técnica de microscopia de força atômica (AFM) para medir o ponto de carga zero $\left(\mathrm{pH}_{\mathrm{pzc}}\right)$ de diversos minerais (quartzo, calcita, sílica de vidro e albita). Estes autores observaram que os aminoácidos adsorvem fortemente sobre os minerais quando $\mathrm{pH}_{\mathrm{pzc}}$ e ponto isoelétrico $(\mathrm{pI})$ apresentam uma diferença significativa. Por este motivo o quartzo $\left(\mathrm{pH}_{\mathrm{pzc}}=2,8\right)$ adsorve fortemente à lisina $(\mathrm{pI}=9,74)$ mas não outros aminoácidos (Asp-pI=2,77; Glu-pI=3,22; Phe-pI=5,48; etc); por outro lado, a calcita $\left(\mathrm{pH}_{\mathrm{pzc}}=9,5\right)$ adsorve fortemente Asp, Glu e Phe e não Lys.

\section{ADSORÇÃO DE AMINOÁCIDOS SOBRE MINERAIS FOI IMPORTANTE PARA A ORIGEM DOS PEPTÍDEOS/ PROTEÍNAS?}

Não existem dúvidas que os minerais podem pré-concentrar aminoácidos, assim como catalisar sua reação para formação de peptídeos. Entretanto, os resultados acima apresentados, levaram Zaia et al. $^{32}$ e Zaia ${ }^{34}$ a proporem algumas questões sobre o papel dos minerais na pré-concentração dos aminoácidos. Klapper ${ }^{35}$ publicou um estudo sobre a composição de aminoácidos em mais de 200 proteínas. Este estudo mostrou que as proteínas têm a seguinte composição de aminoácidos: $40,1 \%$ com grupo R não polar alifático; $8,1 \%$ com grupo R aromático; $25,9 \%$ com grupo R polar não carregado; $11,7 \%$ com grupo $\mathrm{R}$ carregado negativamente e, $13,8 \%$ com grupo $\mathrm{R}$ carregado positivamente ${ }^{35}$. Devemos destacar que as proporções de aminoácidos, com diferentes cadeias laterais nos peptídeos e proteínas, são muito importantes para a conformação destas moléculas e, conseqüentemente, para a bioquímica dos organismos vivos de hoje ${ }^{1}$. Os minerais adsorvem muito mais aminoácidos com grupos $\mathrm{R}$ positiva e negativamente carregados que outros tipos de grupos R. Portanto, este mecanismo produziria peptídeos/proteínas com muito mais aminoácidos com grupos $\mathrm{R}$ carregados que não carregados. Entretanto, 74\% dos aminoácidos das proteínas modernas são constituídos de grupos R não carregados. Em vista do exposto acima, Zaia et $a l .^{32}$ e Zaia ${ }^{34}$ têm questionado quais foram os mecanismos utilizados na produção de peptídeos/proteínas com mais aminoácidos com grupos R não carregados que com grupo R carregados. Deveríamos esperar que a composição dos aminoácidos adsorvidos sobre os minerais fosse a mesma das atuais proteínas? A adsorção de aminoácidos sobre minerais foi importante para a origem da vida? Na próxima seção diversos mecanismos serão discutidos, na tentativa de responder estas questões.

\section{ALGUNS MECANISMOS QUE PODERIAM RESULTAR EM PEPTÍDEOS E/OU PROTEÍNAS COM MAIS AMINOÁCIDOS COM GRUPOS R NÃO CARREGADOS}

Devemos procurar por mecanismos ou substâncias que, a partir de soluções diluídas de aminoácidos, pré-concentrem mais aminoácidos com grupos $\mathrm{R}$ não carregados que com grupos $\mathrm{R}$ carregados, para posterior condensação para peptídeos/proteínas. Devemos também procurar por mecanismos que produzam mais peptídeos/proteínas com uma composição de aminoácidos com grupos $\mathrm{R}$ não carregados que carregados. Apesar da pouca atenção dada pelos pesquisadores em química prebiótica, existem diversos mecanismos que poderiam produzir peptídeos com uma grande proporção de aminoácidos com grupos R não carregados. Podemos dizer que os experimentos em química prebiótica podem ser divididos em dois grandes grupos: no primeiro, os minerais têm uma grande influência na origem da vida e, no segundo, os minerais não têm influência, resultando em uma origem da vida não mineral. Os experimentos do primeiro caso são em maior quantidade, visto que os minerais sempre existiram em nosso planeta e seria lógico imaginar que, em algum ponto, foram importantes para a origem da $v i^{36}{ }^{36}$ Em ambos os casos, peptídeos com grupos $\mathrm{R}$ não carregados podem ser produzidos.

\section{Experimentos envolvendo minerais}

Uma série de aminoácidos foi adsorvida sobre grafita e posteriormente sobre grafita, com prévia adsorção de adenina e hipoxantina ${ }^{37}$. Com grafita pura, os aminoácidos mostraram a seguinte ordem de energia de interação: His $>$ Glu $>\operatorname{Arg} \cong \mathrm{Asp}>\mathrm{Met}$ $>$ Cys. Porém, quando a grafita foi pré-adsorvida com adenina ou hipoxantina, as maiores energias de interação foram observadas para Asp/Glu (grupos R negativamente carregados) e ocorreu uma grande diminuição na energia de interação de His (grupo R positivamente carregado). Este tipo de experimento é muito importante, pois mostra que um pré-RNA mecanismo de seleção de aminoácidos poderia ter existido na Terra primitiva. Isto é, antes do mundo de RNA pode ter existido algo mais simples na seleção de aminoácidos e síntese de peptídeos, que posteriormente evoluiu para o mundo do RNA. No entanto, este mecanismo deveria ser investigado para outros materiais (sílicas, zeolitas, etc.) em combinação com outras bases para verificar se o mesmo seleciona mais aminoácidos com grupos R não carregados.

Reações em ciclos de hidratação (parte aquosa do ciclo) e desidratação (parte seca do ciclo) simulam ambientes que pelo efeito das chuvas ou marés (hidratação), pequenas lagoas, poças de água ou mesmo lamaçais são formados; pelo efeito do calor do sol (desidratação), a água é evaporada podendo deixar estes lugares totalmente secos e, depois de algum tempo, novamente estas lagoas são formadas por chuvas ou marés e novamente pelo efeito do calor do sol são secadas ${ }^{36,38}$ (Figura 1). Diversos grupos de pesquisadores têm utilizado este tipo de ambiente para poderem obter peptídeos. No entanto, o principal objetivo na maioria desses experimentos é mostrar a formação de peptídeos e a faixa de peso molecular dos mesmos. Assim, existem poucos experimentos mostrando a composição dos peptídeos formados a partir de diferentes composições iniciais de aminoácidos. Yanagawa et al. ${ }^{39}$ estudaram a formação de polipeptídios em ciclos de hidratação/desidratação, usando como fonte de aquecimento as microondas e como catalisador/adsorverdor a argila caulinita, com a seguinte composição inicial de aminoácidos 


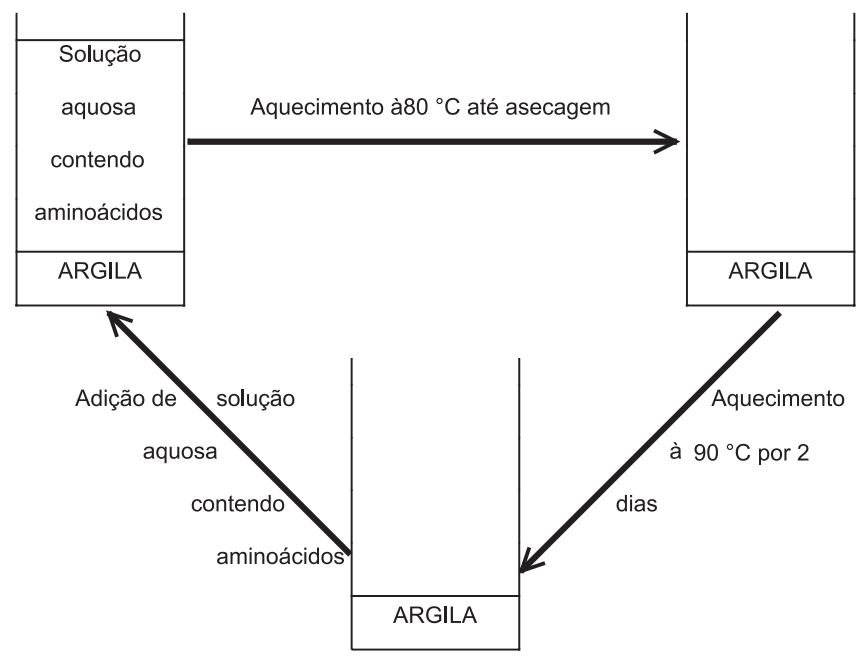

Figura 1. Esquema comumente utilizado no estudo de ciclos de hidratação e desidratação.

(0,1 mol L-1 cada): glicinamida, alaninamida e valinamida (todos com grupos não polares alifáticos), e ácido aspártico $\alpha$-amida (grupo $\mathrm{R}$ negativamente carregado). A análise da composição dos aminoácidos nos peptídeos mostrou que a glicinamida foi incorporada aos polipeptídios 1,5 vezes mais que alaninamida, valinamida e ácido aspártico $\alpha$-amida, os quais foram incorporados nos peptídeos quase na mesma proporção da sua concentração inici$\mathrm{al}^{39}$. Suwannachot e Rode ${ }^{40}$ estudaram a influência catalítica de aminoácidos e peptídeos $\left(\mathrm{Gly}_{2}, \mathrm{DKP}, \mathrm{Ala}_{2}\right)$ na formação de dipeptídeos $\mathrm{Val}_{2}$ e Leu Le $_{2}$ grupos R não polar alifáticos) $\mathrm{Lys}_{2}$ (grupo $\mathrm{R}$ positivamente carregado) utilizando ciclos de hidratação/desidratação com 0,5 mol L-1 de $\mathrm{NaCl} / 0,040 \mathrm{~mol} \mathrm{~L}^{-1}$ de $\mathrm{Cu}^{2+}$ (formação de peptídeo induzida por sais -SIPF). O melhor rendimento foi obtido para Val ${ }_{2}$ usando Gly, His, Gly ${ }_{2}$ ou DKP como catalisadores ${ }^{40}$. Plankensteiner et al. ${ }^{41}$ estudaram a formação de dipeptídeos, em ciclos de hidratação/desidratação com $0,5 \mathrm{~mol} \mathrm{~L}^{-1}$ de $\mathrm{NaCl} / 0,040$ mol L ${ }^{-1}$ de $\mathrm{Cu}^{2+}$ (SIPF) mais glicina ou diglicina (catalisadores), utilizando as seguintes combinações de aminoácidos $\left(0,040 \mathrm{~mol} \mathrm{~L}^{-1}\right.$ cada): ácido aspártico/prolina, ácido aspártico/leucina, leucina/ prolina, valina/ácido aspártico, valina/prolina e valina/leucina. Devemos destacar que os aminoácidos leucina, valina e prolina possuem grupos alifáticos não polares e o ácido aspártico possui grupo $\mathrm{R}$ negativamente carregado. Utilizando diglicina como catalisador, os melhores rendimentos obtidos foram: Pro-Pro $>$ ProVal=Asp-Val $>$ Leu-Pro. Quando glicina foi utilizada como catalisador, os rendimentos dos dipeptídeos obtidos não foram diferentes daqueles com diglicina. Segundo Rode ${ }^{42}$, uma importante característica das reações envolvendo SIPF é a formação de algumas seqüências de dipeptídeos, preferencialmente em relação a outras, que aparecem comumente em algumas proteínas. Os resultados acima sugerem que os peptídeos formados utilizando ciclos de hidratação/desidratação incorporam uma quantidade maior de aminoácidos com grupo $\mathrm{R}$ não carregados que com grupos $\mathrm{R}$ carregados, portanto mais experimentos deveriam ser feitos com outras combinações de soluções.

A polimerização de aminoácidos em solução aquosa foi estudada por diversos autores utilizando diferentes condições de reação, sendo estas minerais como agentes catalisadores ou préconcentradores, agentes condensantes para a oligomerização e etc. ${ }^{22,43-48}$. Entretanto, até onde sabemos não existem experimentos mostrando a polimerização de aminoácidos com diferentes soluções iniciais.
A polimerização térmica de aminoácidos em estado sólido com e sem minerais tem sido estudada por diversos autores, entretanto estes experimentos têm mostrado uma grande incorporação de aminoácidos nos peptídeos com grupo $\mathrm{R}$ carregados ${ }^{49-52}$. Este processo de síntese de peptídeos provavelmente não teve importância para a origem dos peptídeos/proteínas.

Areia e quartzo não foram muito utilizados em experimentos envolvendo a adsorção de aminoácidos, principalmente devido à pequena área superficial da mesma quando comparada com argilas. Basiuk ${ }^{6}$ estudou a adsorção de aminoácidos sobre quartzo e observou que, em geral, os aminoácidos com grupos R não carregados adsorvem mais que os aminoácidos com grupos carregados. Por outro lado, Zaia et al. ${ }^{32}$ utilizando areia da praia do Guarujá (SP) observaram justamente o contrário, ou seja, Lys (grupo R positivamente carregado) adsorveu mais que os aminoácidos com grupos R não carregados. Porém, nenhum dos dois autores citados acima realizou experimentos controlando o $\mathrm{pH}$ ou avaliou o efeito dos sais da água do mar na adsorção dos aminoácidos. Desta forma, novos experimentos devem ser realizados para verificar se areia pré-concentra mais aminoácidos com grupos $\mathrm{R}$ carregados ou não carregados. Os seguintes experimentos poderiam ser realizados: quantificação da adsorção dos aminoácidos (Ser/Gln-grupo R polar mas não carregado, Lys/His-grupo R positivamente carregado, Asp-grupo R negativamente carregado e Ala/Met/Phe/Tyr-grupo R apolar) em água destilada em dois $\mathrm{pHs} 5,50 \mathrm{(pH}$ comum perto de hidrotermais) e 7,20 ( $\mathrm{pH}$ da água do mar mais comumente encontrado) sobre quartzo e areia, e repetição do mesmo experimento em água do mar artificial. Estes experimentos podem mostrar qual é o efeito do $\mathrm{pH}$ e dos sais da água do mar na adsorção de aminoácidos sobre quartzo e areia e que tipo de aminoácido é mais adsorvido.

\section{Experimentos não envolvendo minerais}

Segré et al..$^{53}$ propuseram o "Mundo dos Lipídeos" como uma alternativa do mundo do RNA, assim como para a origem da vida. Estas substâncias provavelmente foram muito comuns na Terra primitiva e diversas vantagens podem ser citadas em favor do mundo dos lipídios: estas moléculas se agrupam espontaneamente em complexas estruturas supramoleculares; estas estruturas supramoleculares podem agir como catalisadores e, contêm informação devido sua composição, podendo evoluir ${ }^{54-61}$. A polimerização de glicina dentro de vesículas de lipídios em hidrotermais foi estudada por Tsukahara et l. $^{62}$. Estes autores obtiveram melhores rendimentos de di- ou triglicina com lipídios que sem lipídios, sendo que foi possível sintetizar até mesmo heptaglicina ${ }^{62}$. A polimerização de aminoácidos dentro de vesículas de lipídios é um experimento muito interessante em termos de química prebiótica visto que não há necessidade de catalisadores e, dentro das vesículas, os peptídeos ficam protegidos do meio ambiente, evitando assim sua perda. No entanto, experimentos deveriam ser realizados com diferentes composições de aminoácidos para se verificar que tipos de aminoácidos seriam mais incorporados aos peptídeos. Utilizando o agente condensante lipofílico 2-etoxi-1-etoxicarbonil-1,2diidroquinolina (EEDQ), Blocher et al. ${ }^{63}$ e Luisi et al. ${ }^{64}$ mostraram que as membranas de lipossomas podem contribuir para o elongamento de peptídeos, assim como selecionar aminoácidos e peptídeos hidrofóbicos, funcionando como uma ferramenta de seleção na polimerização. Esses autores também mostraram que quando a membrana era negativamente carregada, peptídeos contendo Arg e His (grupos R positivamente carregados) foram obtidos ${ }^{65}$. Por outro lado, quando a membrana era positivamente carregada (cetiltrimeti de brometo de amônio), peptídeos contendo Asp e Glu 
(grupos R negativamente carregados) foram obtidos ${ }^{66}$. Estes experimentos mostram um mecanismo pelo qual aminoácidos hidrofóbicos poderiam ter sido selecionados.

\section{CONCLUSÃO}

Os minerais adsorvem muito mais aminoácidos com grupos $\mathrm{R}$ carregados que não carregado, portanto, a subseqüente polimerização destes aminoácidos poderia produzir peptídeos/proteínas com uma grande quantidade de aminoácidos com grupos $\mathrm{R}$ carregados. Porém, as proteínas dos seres vivos atuais são constituídas de $74 \%$ de aminoácidos com grupos $\mathrm{R}$ não carregados. Foram discutidos neste artigo diversos mecanismos que poderiam estar envolvidos na produção de peptídeos/proteínas com uma grande proporção de aminoácidos com grupos $\mathrm{R}$ não carregados. De todos os experimentos aqui discutidos devemos destacar dois e, em ambos, os lipídios estão envolvidos. No primeiro caso, lipídeos (como sugerido no mundo dos lipídios) em hidrotermais podem ser uma alternativa interessante para a síntese de peptídeos, visto que não há necessidade de catalisadores ou minerais para adsorção dos aminoácidos. No segundo caso, lipossomos selecionaram aminoácidos e peptídeos hidrofóbicos e isto poderia explicar porque $74 \%$ dos aminoácidos das proteínas modernas são hidrofóbicos. Portanto, o mecanismo de pré-concentrar os aminoácidos realizado pelos minerais pode não ter sido tão importante quanto se imaginava.

\section{REFERÊNCIAS}

1. Bilgen, T. Em Functional and Metabolism: Regulation and Adaptation; Storey, K. B., ed.; Wiley-Liss, John Wiley and Sons Inc.: Hoboken, 2004, cap. 20; Darnell, J.; Lodish, H.; Baltimore, D.; Molecular Cell Biology, Scientific American Books: New York, 1990, p. 48.

2. Miller, S. L.; Science 1953, 117, 528.

3. Schlesinger, G.; Miller, S. L.; J. Mol. Evol. 1983, 19, 376.

4. Hirose, Y.; Ohmuro, K.; Saigoh, T.; Yamagata, Y.; Orig. Life Evol. Biosph. 1990-1991, 20, 471.

5. Kobayashi, K.; Kaneko, T.; Saito, T.; Oshima, T.; Orig. Life Evol. Biosph. 1998, 28, 155 .

6. Basiuk, V. A. Em Encyclopedia of Surface and Colloid Science, Adsorption of biomolecules on silica; Somasundaran, P., ed.; Marcell Dekker Inc.: New York, 2002, p. 277.

7. Weber, A. L.; J. Mol. Evol. 1982, 18, 354.

8. Ferris, J. P.; Hagan Jr., W. J.; Tetrahedron 1984, 40, 1093.

9. Sakurai, M.; Yanagawa, H.; Orig. Life 1984, 14, 171.

10. Onoe, J.; Kawai, T.; J. Chem. Soc., Chem. Commun. 1987, 1481.

11. Holm, N. G.; Orig. Life Evol. Biosph. 1992, 22, 5.

12. Engel, M. H.; Macko, S. A.; Precambrian Res. 2001, 106, 35.

13. Bernstein, M. P.; Dworkin, J. P.; Sandford, S. A.; Cooper, G. W.; Allamandola, L. J.; Nature 2002, 416, 401.

14. Bernal, J. D.; The Physical Basis of Life, Routledge and Kegan Paul Ltd.: London, 1951.

15. Odom, D. G.; Rao, M.; Lawless, J. G.; Oro, J.; J. Mol. Evol. 1979, 12, 365.

16. Rishpon, J.; O’Hara, P. J.; Lahav, N.; Lawless, J. G.; J. Mol. Evol. 1982, $18,179$.

17. Tessis, A. C.; Penteado-Fava, A.; Pontes-Buarque, M.; de Amorim, H. S.; Bonapace, J. A. P.; de Souza-Barros, F.; Vieyra, A.; Orig. Life Evol. Biosph. 1999, 29, 361.

18. Pontes-Buarque, M.; Tessis, A. C.; Bonapace, J. A. P.; Monte, M. B. M.; Cortés-Lopez, G.; de Souza-Barros, F.; Vieyra, A.; Orig. Life Evol. Biosph. 2001, 31, 343 .

19. Prabahar, K. J.; Ferris, J. P.; J. Am. Chem. Soc. 1997, 119, 4330.

20. Sowerby, S. J.; Cohn, C. A.; Heckl, W. M.; Holm, N. G.; Proc. Nat. Acad. Sci. U.S.A. 2001, 98, 820 .
21. Boclair, J. W.; Braterman, P. S.; Brister, B. D.; Jiang, J.; Lou, S.; Wang, Z.; Yarberry, F.; Orig. Life Evol. Biosph. 2001, 31, 53.

22. Ferris, J. P.; Hill Jr., A.; Liu, R.; Orgel, L. E.; Nature 1996, 381, 59

23. Zamaraev, K. I.; Romannikov, V. N.; Salganik, R. I.; Wlassoff, W. A.; Khramtsov, V. V.; Orig. Life Evol. Biosph. 1997, 27, 325.

24. Hill Jr., A.; Orgel, L. E.; Orig. Life Evol. Biosph. 1999, 29, 115.

25. Ferris, J. P.; Orig. Life Evol. Biosph. 2002, 32, 311.

26. Lahav, N.; Chang, S.; J. Mol. Evol. 1976, 8, 357.

27. Paecht-Horowitz, M; Orig. Life 1978, 289.

28. Tanaka, H.; Miyajima, K.; Nakagaki, M.; Shimabay, S.; Chem. Pharm. Bull. 1989, 37, 2897.

29. Henrichs, S. M.; Sugai, S. F.; Geochim. Cosmochim. Acta 1993, 57, 823.

30. Bentaleb, A.; Vera, P.; Delgado, A. V.; Gallardo, V.; Mater. Chem. Phys. 1994, 37, 68

31. Mellersh, A.; Wilkinson, A. S.; Orig. Life Evol. Biosph. 2000, 30, 3.

32. Zaia, D. A. M.; Vieira, H. J.; Zaia, C. T. B. V.; J. Braz. Chem. Soc. 2002, 13,679

33. Churchill, H.; Teng, H.; Hazen, R. M.; Am. Mineral. 2004, 89, 1048.

34. Zaia, D. A. M.; Amino Acids 2004, 27, 113.

35. Klapper, M. H.; Biochem. Biophys. Res. Commun. 1977, 78, 1018.

36. Lahav, N.; Het. Chem. Rev. 1994, 1, 159

37. Sowerby, S. J.; Petersen, G. B.; Holm, N. G.; Orig. Life Evol. Biosph. 2002, 32,35 .

38. Zaia, D. A. M.; Química Nova 2003, 26, 260; Zaia, D. A. M.; Semina 2004, 25,3 .

39. Yanagawa, H.; Kojima, K.; Ito, M.; Handa, N.; J. Mol. Evol. 1990, 31, 180.

40. Suwannachot, Y.; Rode, B. M.; Orig. Life Evol. Biosph. 1999, $29,463$.

41. Plankenseiner, K.; Righi, A.; Rode, B. M.; Orig. Life Evol. Biosph. 2002, $32,225$.

42. Rode, B. M.; Peptides 1999, 20, 773

43. Liu, R.; Orgel, L. E.; J. Am. Chem. Soc. 1997, 119, 4791

44. Hill Jr., A.; Bohler, C.; Orgel, L. E.; Orig. Life Evol. Biosph. 1998, 28, 235.

45. Imai, E .I.; Honda, H.; Hatori, K.; Matsuno, K.; Orig. Life Evol. Biosph. 1999, 29, 249

46. Ogata, Y.; Imai, E. I.; Honda, H.; Hatori, K.; Matsuno, K.; Orig. Life Evol. Biosph. 2000, 30, 527.

47. Alargov, D. K.; Deguchi, S.; Tsujii, K.; Horiloshi, K.; Orig. Life Evol. Biosph. 2002, 32, 1 .

48. Yokoyama, S.; Koyama, A.; Nemoto, A.; Honda, H.; Imai, E. I.; Hatori, K.; Matsuno, K.; Orig. Life Evol. Biosph. 2003, 33, 589.

49. Phillips, R. D.; Melius, P.; J. Protein Res. 1974, 6, 309.

50. Saunders, M. A.; Rohlfing, D. L.; BioSystems 1974, 6, 81.

51. Rohlfing, D. L.; McAlhaney, W. W.; BioSytems 1976, 8, 139.

52. Hartmann, J.; Brand, M. C.; Dose, K.; BioSystems 1981, 13, 141.

53. Segré, D.; Ben-Eli, D.; Deamer, D. W.; Lancet, D.; Orig. Life Evol. Biosph. 2001, 31, 119 .

54. Luisi, P. L.; Giomini, M.; Pileni, M. P.; Robinson, B, H.; Biochim. Biophys. Acta 1988, 947, 209.

55. Bachmann, P. A.; Walde, P.; Luisi, P. L.; Lang, J.; J. Am. Chem. Soc. 1990, 112,8200

56. Bachmann, P. A.; Walde, P.; Luisi, P. L.; Lang, J.; J. Am. Chem. Soc. 1991, 113, 8204.

57. McCollom, T. M.; Ritter, G.; Simoneit, B. R. T.; Orig. Life Evol. Biosph. 1999, 29, 153.

58. Wick, R.; Luisi, P. L.; Chem. Biol. 1996, 3, 277.

59. Rushdi, A. I.; Simoneit, B. R. T.; Orig. Life Evol. Biosph. 2001, 31, 103.

60. Oberholzer, T.; Nierhaus, K. H.; Luisi, P. L.; Biochem. Biophys. Res. Comm. 1999, 261, 238.

61. Fischer, A.; Oberholzer, T.; Luisi, P. L.; Biochim. Biophys. Acta 2000, 1467, 177.

62. Tsukahara, H.; Imai, E. I.; Honda, H.; Hatori, K.; Matsuno, K.; Orig. Life Evol. Biosph. 2002, 32, 13

63. Blocher, M.; Liu, D.; Walde, P.; Luisi, P. L.; Macromolecules 1999, 32, 7332 .

64. Luisi, P. L.; Walde, P.; Blocher, M.; Liu, D.; Chimia 2000, 54, 52.

65. Blocher, M.; Liu, D.; Walde, P.; Luisi, P. L.; Macromolecules 2000, 33, 5787.

66. Böhler, C.; Hill Jr., A. R.; Orgel, L. E.; Orig. Life Evol. Biosph. 1996, $26,1$. 